\title{
LAS REPRESENTACIONES COLECTIVAS \\ DE LOS PUEBLOS INDOEUROPEOS
}

Miguel Requena y Díez de Revenga

Mitos y Leyendas; Religión y Politica

En el Canto XIX de la Odisea, Homero ha registrado una significativa descripción de la realeza helénica. Ulises, interrogado por Penélope acerca de su identidad, su linaje y su procedencia, compara a aquélla con un rey eximio $\mathrm{y}$ temeroso de los dioses que «reina sobre muchos y valerosos hombres, y hace que triunfe la justicia y que produzca la negra tierra trigo y cebada y que se inclinen los árboles por el fruto, y que las ovejas paran robustas y el mar produzca peces por su buen gobierno, y que el pueblo sea próspero bajo su cetro» (Homero, 1976, Canto XIX: 107 y ss.). Un tanto desdibujadas, aparecen en el canto homérico las tres funciones que debe cumplir un rey que se precie de tal dignidad. A saber: la ordenación justa de su reino; el ejercicio de la fuerza para defensa de sus súbditos, y la prosperidad material de sus dominios. Lejos de ser únicamente un artificio retórico que el poeta pone en boca de Ulises para mayor alabanza de Penélope, con ocasión de su mutuo reencuentro, esta fórmula homérica expresa la más arcaica estructura en la que los pueblos indoeuropeos han codificado su representación de la Soberanía.

«Se lee en una inscripción persa aqueménida de Darío la expresión de una oración para desterrar del país tres calamidades: dusiyara 'la mala cosecha', 
baina 'el ejército enemigo', drauga 'la mentira', es decir, la perversión en el orden moral y religioso. Esta no es una formulación azarosa. Estas tres calamidades responden a un orden necesario» (Benveniste, 1969, tomo I: 288-9). Darío invoca la ayuda de Alhuramazda para evitar estas tres desgracias en su reino. Este conjunto de males representan la figura invertida de lo que un buen rey debe procurar a su pueblo: una justa administración en el terreno de la moral y la religión; la protección de sus gentes mediante la práctica de la guerra, y el bienestar material de sus súbditos.

La figura helénica de la realeza que Homero plasma en su canto, en los siglos XIII-XII a. C., no es otra que la que se contiene en la oración de Darío (siglos vI-v a. C.). Los pueblos indoeuropeos conciben la Soberanía estructurada en estas tres funciones, hecho que se manifiesta en sus más genuinas expresiones mitopoéticas y en sus oraciones.

La extensísima área geográfica en la que se asientan las culturas indoeuropeas ha conocido esta representación triádica de la Soberanía. El «mitologema» de la Soberanía está compuesto siempre de las tres funciones básicas que aseguran la permanencia de la comunidad en su esfuerzo por perpetuarse y reproducirse. Sólo mediante la adecuada conjunción de estas tres funciones se garantiza el Orden de la sociedad, necesaria premisa de su automantenimiento. La descripción homérica del «rey eximio» y la oración de Darío no expresan otra cosa que las condiciones de posibilidad del existir firme y duradero de una comunidad indoeuropea. La figuración indoeuropea de la Soberanía no se concibe sino como cumplimiento armonioso de la administración de lo sagrado y la justicia; de la violencia física y guerrera, y de una productividad adecuada. Más allá de esto, sólo hay muerte: el incumplimiento de alguna de las tres funciones genera el caos, la extinción de la sociedad. La representación trifuncional de la Soberanía significa para las comunidades indoeuropeas las condiciones de su supervivencia. La representación de la Soberanía triádica es el símbolo de la autoidentificación colectiva de los indoeuropeos, en tanto que así se garantiza su permanencia como tales. La perdurabilidad de la sociedad queda asegurada solamente cuando se cumple la estructura trifuncional de la Soberanía. Al definir las condiciones de un cierto Orden Social, Duradero y Permanente, los indoeuropeos encierran en la representación triádica de la Soberanía la posibilidad de seguir siendo. Las comunidades indoeuropeas son y existen solamente en la medida en la que pueden seguir siendo y existiendo; esto es, siguen siendo y existiendo sólo si y cuando cumplen las tres funciones soberanas. El ritual de la Soberanía es la premisa de la Identidad Colectiva; los pueblos indoeuropeos se identifican colectivamente con una figura específica del Orden Social: aquella figura en la que viene dado el ritualizado cumplimiento de la administración de lo sagrado y de la justicia; el ritualizado ejercicio de la violencia guerrera y el conjunto ritual de la producción.

«Las bandas de conquistadores arios que, en el curso del segundo milenio 
antes de Jesucristo, se expandieron desde Siria al Indo, los del oeste para una dominación efímera, los del centro y del este para triunfos definitivos, llevaban con ellos una explicación del mundo y de la sociedad a la vez simple y poderosa. Las fuerzas que animan a uno y a otra, pensaban ellos, se agrupan, en lo esencial, sobre tres niveles jerárquicamente ordenados y cósmicamente superpuestos, de los cuales los dos primeros se dejan nombrar con una palabra rápida: soberanía mágica y jurídica; vigor guerrero; en cuanto al tercero, es más complejo, aunque se siente el factor común de sus manifestaciones: salud y alimentación, abundancia en hombres y en bienes, apego al sol, y también paz, aspiración al disfrute tranquilo de una edad de oro» (Dumézil, 1969: 195).

Desde sus primitivos focos de irradiación y expansión lingüístico-cultural, una misma concepción del mundo y de la sociedad se extiende paulatinamente por los dominios indoeuropeos; esta concepción supone que la sociedad y el mundo se sostienen a partir de la administración religiosa y jurídica, mediante el ejercicio de la violencia bélica y cuando existe abundancia de alimentos, salud, etc. La estructura de esta cosmovisión es, en efecto, la misma que la de la soberanía. El mundo en su totalidad y en cada uno de sus niveles específicos no puede existir, mantenerse y reproducirse más que en virtud del armonioso ejercicio del poder soberano, de la fuerza física y de la fecundidad.

Ahora bien, la representación de la soberanía que concibieron los pueblos indoeuropeos descansa en la articulación de sus sociedades a partir de los grupos de actividad que tienen a su cargo el ritualizado cumplimiento de las tres funciones. En los mundos indoeuropeos encontramos que los tres grupos que componen la sociedad son: sacerdotes, guerreros y agricultores-ganaderos. «Según las tradiciones indoiránicas la sociedad está organizada en tres clases de actividad: sacerdotes, guerreros y cultivadores. En la India védica estas clases se llaman "colores", varna. En Irán tienen por nombre pistra, oficio, cuyo sentido etimológico es también color. Hay que tomar la palabra en su acepción literal: son en efecto colores. Es por el color de sus vestimentas cómo se distinguen las tres clases en Irán -el blanco para los sacerdotes, el rojo para los guerreros, el azul para los cultivadores, en virtud de un simbolismo profundo que procede de antiguas clasificaciones conocidas en muchas cosmologías...» (Benveniste, op. cit., 1969: 279).

La India védica, de la que conservamos testimonios escritos que datan de unos mil años antes de Jesucristo, conoció un sistema de castas entre las que es posible distinguir: los brabmanes, sacerdotes que representan la primera de las funciones soberanas; los ksattriya o guerreros; los vaisya o productores en general. En el Irán avéstico - circa 500 a. C.-, las tres funciones están a cargo, respectivamente, de los atbravan, los ratbaestar y los vastryo fsuyant. "Los dos grupos de términos difieren en su naturaleza lexical, pero concuerdan en su referencia social. La división tripartita de la sociedad es la más antigua que podemos alcanzar. Tiene prolongaciones históricas que 
no han sido siempre reconocidas, especialmente en la sociedad india... las castas de la India son la sistematización muy endurecida que se remonta en todo caso al pasado indoiranio, quizá incluso ya a la sociedad indoeuropea» (Benveniste, op. cit., p. 280).

El minucioso análisis etimológico de estos términos que realiza Benveniste nos muestra su significado primario. El brahman es aquel que asegura la ejecución del culto según las formas prescritas: es el representante de la primera función. La segunda función está atribuida a los ksattriya (guerreros dotados de una cierta potencia mágica), en la India, y a los rathaestar (los combatientes en carro), en Irán. La denominación vastryo fsuyant para los representantes de una tercera función encierra un doble significado: de un lado, el pastoreo; de otro, la cría de rebaños.

Esta representación de la articulación interna de la sociedad coincide término a término con el «mitologema» indoeuropeo de la Soberanía: hablando con propiedad, estamos ante la misma figura. Tal figura está presente en la práctica totalidad del área conquistada por los indoeuropeos. Se puede inferir, por tanto, que corresponde a la visión que de sí mismas tuvieron las más primitivas comunidades indoeuropeas. «¿Esta división, que abarca la totalidad de los hombres, está limitada a la sociedad indoirania? Se puede pensar que es muy antigua y que se remonta al pasado indoeuropeo. De hecho, ha dejado huellas por todas partes. Señalaremos en particular, en Grecia, las tradiciones legendarias sobre la primera organización de la sociedad jónica. Queda un reflejo de ella en el mito relativo a los hijos de Ion, el epónimo de la raza" (Benveniste, op. cit., p. 289).

Señalemos que la misma representación de su sociedad que conoció el área indoirania y el mundo helénico aparecerá más tarde en las culturas germánicas. Julio César, en De Bello Gallico, distingue entre la población pagana de la Galia tres grupos significativos: druidas, equites y plebe. Los documentos que describen el estado social de la Irlanda pagana y también, poco después, de su conversión al cristianismo nos muestran una sociedad estructurada en tres niveles jerárquicos. El más alto escalón lo ocupan los druidas, sacerdotes, magos y juristas depositarios de las tradiciones; por debajo de éstos encontramos a la aristocracia militar, los flaith irlandeses; por último, en el nivel más bajo de la escala social están los boairing, hombres libres poseedores de vacas.

Constatamos, pues, la identidad estructural que existe entre las representaciones de la Soberanía y la Sociedad para los pueblos indoeuropeos. La estructura trifuncional sobredetermina estas representaciones simbólicas de la Soberanía y la Sociedad: a una precisa imagen de la Soberanía corresponde la misma imagen de la Sociedad, que no es otra que la de las tres funciones.

Ahora bien, «la religión legitima las instituciones sociales otorgándoles un status ontológico válido en última instancia, esto es, colocándolas dentro de un marco de referencia cósmico y sagrado. Las construcciones históricas 
de la actividad humana son consideradas desde un punto de vista elevado, que, según su autodefinición, trasciende tanto al hombre como a su historia misma. Probablemente la fórmula más antigua de esta legitimación es la concepción del orden institucional como un reflejo o una manifestación directa de la estructura divina del cosmos, es decir, la concepción de la relación entre la sociedad y el cosmos como una relación entre un microcosmos y un macrocosmos» (Berger, 1971: 57-8).

El argumento teórico de Berger se manifiesta con indudable claridad en el ámbito de las culturas indoeuropeas. La misma estructura que informa las figuraciones de la Soberanía y de la Sociedad sobredetermina al tiempo el conjunto del «mundo imaginario» de los dioses. La sociedad de los hombres «se ha formado», de esta suerte, a imagen de la Sociedad de los Dioses. La estructura de la mitología religiosa de los pueblos indoeuropeos se identifica absolutamente con la estructura de la representación de su estructura social. La sociedad divina funciona, por tanto, como imago arquetípica de la sociedad humana, pues la sociedad divina define las condiciones de supervivencia de la sociedad de los hombres. La religión confiere a la realidad social una sobrelegitimación fundamental: la Sociedad de los Dioses es, por su propia definición, atemporal e imperecedera; la sociedad de los hombres, en cambio, se define por su carácter histórico-temporal. Sólo concibiendo esta sociedad de los hombres a imagen y semejanza de aquella Sociedad de los Dioses se la imagina como eterna.

Por consiguiente, los indoeuropeos han imaginado la sociedad divina con los caracteres de trifuncionalidad que ya conocemos. Las tres funciones del soberano, las tres funciones de los grupos que componen la estructura social, son asumidas igualmente por las deidades. Los indoeuropeos imaginan a sus dioses como los más fundamentales representantes de la figura trifuncional.

Desde hace aproximadamente cincuenta años, las eruditas investigaciones de Georges Dumézil nos vienen legando magistrales análisis de la religión y la mitología de los pueblos indoeuropeos. Estas investigaciones ponen al descubierto la estructura que soporta las construcciones religiosas de estos pueblos.

Efectivamente, los más principales dioses se reparten las tres funciones básicas de la comunidad: «Estas funciones son: 1) la administración a la vez misteriosa y regular del mundo; 2) el juego del vigor físico, de la fuerza, principalmente guerrera; 3) la fecundidad, con muchas condiciones, tales como la prosperidad, la salud, la longevidad, la tranquilidad, la voluptuosidad, la gran cantidad» (Dumézil, 1970: 12).

La primera función viene desempeñada, para la India védica, por dos dioses emparejados de forma complementaria: Mitra, pacífico, fundador del orden de la comunidad, protector de las relaciones institucionalizadas, divinización del Contrato y la Ley, y Varuna, temible, violento, misterioso, administrador privilegiado de la «maya», la potencia mágica. 
Indra asume la representación litúrgica de la segunda función. Brutal significante de la Fuerza, Indra tiene la misión de salvar al mundo (= la comunidad) mediante el «salvaje» ejercício de la guerra.

Los gemelos Nasatya representan el complejo ritualizado de la tercera función. Donadores de salud, dioses de la fecundidad, de la incesante profusión de bienes y víveres; en suma, productores.

A cada uno de estos dioses está asociada una región del mundo. Mundo que, no hay que olvidarlo, se va empapando profundamente de significado; de tal suerte que aquel mundo deviene paulatinamente Cosmos. Los dominios de Mitra y Varuna se extienden a la bóveda celeste, la envoltura del mundo; Indra sienta su imperio en la capa atmosférica (las nubes, el viento); los dioses productores de la tercera función recorren el espacio terrestre, el suelo y el subsuelo.

La especificidad de esta estructura se pone de manifiesto si se la compara con la que parece más extendida en otras sociedades. A riesgo de caer en una generalización espúrea, hay que señalar que lo más frecuente ha sido concebir una división inicialmente bipartita de los dioses: de un lado, los dioses uránicos; de otro, los dioses ctónicos (o, más precisamente, las diosas). Eliade ha señalado hasta la saciedad cómo la hierogamia primordial del Cielo y la Tierra, el coito sagrado entre el Cielo-fecundador y la Gran Tierra-Madre, el mito cosmogónico por excelencia, funda el Cosmos (Eliade, 1973 y 1978, passim). Sin embargo, entre los indoeuropeos la estructura es tripartita. Dice Dumézil de la ideología religiosa de los indoeuropeos: «En el mundo antiguo -Europa, Asia, Africa del Norte- esta ideología activa no se encuentra más que entre los pueblos que hablaban lenguas indoeuropeas y entre algunos pueblos limítrofes de los cuales está asegurado, a veces con precisión de datos, que ellos han estado expuestos a la influencia de los Indo-Europeos. En particular, ni las sociedades semíticas del Próximo Oriente, ni las sociedades siberianas, ni la China la han practicado: esta última, por ejemplo, como los Turcos más antiguamente conocidos, hundía su frondosa reflexión, especialmente su teología, en un molde binario (Cielo y Tierra, alto y bajo; socialmente: el mandatario del Cielo y todo el resto)» (Dumézil, 1979: 80).

Antes de pasar a Roma y a los pueblos germánicos, sólo señalar cómo la reforma monoteísta que llevó a cabo, en Irán, Zarathustra no logra impedir que la estructura trifuncional aflore en la teología reformada. Bajo el imperio de Ahura-Mazda, singular arquetipo de la primera función, aparece en las restantes funciones un desdoblamiento en arcángeles y demonios que traduce el dualismo cosmológico, ético y religioso propio del zoroastrismo. Xsatra y Armaitia, Indra y Nanhaitia son, respectivamente, arcángeles y demonios, representantes de la segunda y de la tercera función.

Conviene ahora detenerse en Roma para fijarse en las primeras formas religiosas que alli se conocieron. El atento examen de Dumézil nos revela una y la misma estructura triádica que ya se vio en la India védica. «La 
tríada de dioses jerarquizados, a cuyo servicio está un flamen mayor, es lo más antiguo que conocemos de la teología de Roma. Remontándonos a lo más remoto, observamos efectivamente que en la cabeza de todo el cuerpo sacerdotal, cediendo el paso solamente al rex, hay tres flámines mayores afectos a Júpiter el uno, a Marte el segundo, y a Quirino el tercero, en orden decreciente» (Dumézil, op. cit., 1970: 29). No se trata de un mero parecido: en el plano de la estructura, la identidad es perfecta. A la cabeza de los dioses se encuentra Júpiter, protector y salvaguarda de la ciudad. Preside la batalla, pero no entra en combate; es definitivamente el más decidido garante del Orden. El aspecto Ley, Contrato, viene representado en Roma por Dios Fidius. Aparece así la pareja de la primera función: el dios de las grandes acciones y el dios jurista.

En el plano jerárquico inmediatamente inferior se sitúa Marte. Dios de la fuerza física canalizada hacia la guerra, Marte se corresponde con el védico Indra.

La más polimorfa de las funciones (mas no por eso menos coherente) es significada por Quirino, dios de la fecundidad y las riquezas, de la paz y de la tierra, ligado indisolublemente a la producción y a la reproducción. Dumézil ha reconstruido los aspectos de este dios a partir de los servicios y oficios del sacerdote que se consagra a esta divinidad. «¿Cuáles son los oficios del flamen quirinalis? El 25 de abril sacrifica en los Robigalia y pone en las armas guerreras el añublo que amenaza las espigas. El 21 de agosto sacrifica en los Consualia, en el altar subterráneo de Consus, dios de la cosecha guardada en el granero. Dos días más tarde honra a Quirino, al mismo tiempo que a la pareja de Consus, Ops Opifera, divinidad completamente rural, en un sacrificio ofrecido in colle contra los incendios, seguramente en los graneros. El 23 de diciembre, el flamen quirinalis sacrifica en la tumba de Larencia a la cortesana-donadora que, en una historia célebre, encarna la voluptuosidad, la riqueza y la generosidad. Añadamos que los Quirinalia, fiesta propia de Quirino, el 17 de febrero, coincide con el último acto de los Fornacalia, es decir, las fiestas curiales de la torrefacción de los granos» (Dumézil, op. cit., 1970: 32-3). Por otra parte, Benveniste ha indicado que la etimología del término Quirino se refiere a la «masa de hombres».

Por último, en los paganismos germánicos, los dioses canónicos de la soberanía se reparten en la tríada funcional que ya nos es conocida. Odinn, Thorr y Freir son los dioses que corresponden a las tres funciones en el área escandinava. Y, como tales, se encuentran figurativamente representados en el antiguo templo de Upsala, al norte de Suecia. Odinn es el soberano de los dioses y de la potencia mágica. Thorr, incansable guerrero que, con su potente martillo, no cesa de batirse con los gigantes que amenazan al mundo. Por último, Freir (en ocasiones acompañado de Njordr) es el maestro de la riqueza, de la abundancia, de la voluptuosidad. Para el área especialmente ger- 
mana contamos con el testimonio de Tácito -en La Germania-, quien, transponiendo a aquel ámbito la nomenclatura latina, señaló la presencia de Mercurio, Hércules y los gemelos Alcis.

En lo que toca a la epopeya, «algunas de las expresiones más útiles de la ideología de las tres funciones se hallan, en efecto, en las obras épicas: incluso en el seno de sociedades en las que esa ideología había perdido muy pronto toda actualidad ha guardado el suficiente prestigio para mantener, a través de los siglos, narraciones heroicas, a veces muy populares. Esto sucede especialmente en tres pueblos: los indios, con el Mahabharata; los romanos, con la «historia» de sus orígenes, y, finalmente, los osetas, últimos descendientes de los escitas, que constituyen un pequeño pueblo del Cáucaso del Norte, ... con su leyenda sobre los héroes nartos» (Dumézil, 1977: 17).

En el Mahabharata, la arcaica estructura mítica de los dioses de las tres funciones se proyecta en el plano de los héroes, de los Pandava. El poema épico reproduce constantemente, ahora aplicadas al plano humano de los héroes, estructuras mítico-teológicas arcaicas. Otra cosa es que tales estructuras míticas, que los poetas han reproducido, reciban eventuales modificaciones. De cualquier modo, bajo la turbulencia de las modificaciones, los cambios de nomenclatura, las divinidades ausentes..., Dumézil nos muestra la misma y única estructura que mantiene los noventa mil versos del poema: la estructura de las tres funciones. Valga como muestra de ello este esquema sintético:

\section{RigVeda}

\section{Mababharata}

\begin{tabular}{|c|c|c|}
\hline \multirow{2}{*}{ Argo can } & \multirow[b]{2}{*}{ Dioses } & \multirow[b]{2}{*}{ Héroes } \\
\hline & & \\
\hline Mitra-Varuna & Dharma & Yudhisthira \\
\hline Indra & Vayu-Indra & Bhima-Arjuna \\
\hline Nasatya & Asvin & Nakula-Shadeva \\
\hline
\end{tabular}

En Roma, una "historia» (que hace alusión a razas, edades, dinastías...) ha sido compuesta mediante la colocación en sucesión cronológica, siguiendo un orden descendente de enumeración, de representantes de las tres funciones. En Roma, el mito se historiza, conservando su antigua estructura. Según la leyenda, los reyes romanos preetruscos son: 1) Rómulo, que establece la constitución política; 2) Numa, que establece los cultos rituales: religión y justicia; 3) Tulo Hostilio, que instaura la técnica de la guerra, y 4) Anco Marcio, que se preocupa de la expansión demográfica y económica.

Los historiadores - Tito Livio, Plutarco, Dionisio de Halicarnaso-, y también los poetas - - Virgilio, Propercio-, llevan la estructura de las tres funciones al campo étnico. Las tres etnias que concurren a la formación de 
Roma, los protorromanos de Rómulo, los etruscos de Lucumón, los sabinos de Tito Tacio, representan las tres funciones. En la Eneida, de Virgilio, serán los troyanos de Eneas, los rútulos de Tarcón y los latinios de Latino.

Al igual que en Roma, conocemos en Grecia una fabulación mítica referente al origen de la sociedad humana donde se hace presente, una vez más en otro dominio indoeuropeo, el mitologema de las tres funciones. En Los Trabajos y los Días, Hesiodo relata la sucesión de las diversas razas de hombres que concurren a la formación de la sociedad: las razas de oro, de plata, de bronce, de los héroes y del hierro. «El análisis detallado del mito confirma y precisa en todos los puntos el esquema que desde el comienzo habían parecido imponernos las grandes articulaciones del texto: no cinco razas que se suceden cronológicamente según un orden de decadencia más o menos progresivo, sino una construcción en tres planos, en la cual cada peldaño se divide en dos aspectos opuestos y complementarios» (Vernant, 1975: 35). La reelaboración del viejo mito indoeuropeo en la sociedad griega conoce una articulación más sofisticada. Cada uno de los tres niveles del mitologema trifuncional se despliega ahora en dos aspectos que expresan, respectivamente, la diké (justicia, ley) y la hubris (desmesura). La raza de los hombres de oro expresa el aspecto reglado de la primera función, mientras que la raza de plata es su versión desbordada. Lo mismo ocurre con las razas de los héroes y del bronce. Por último, en la raza de hierro se contienen, al tiempo, los aspectos reglados y desmesurados de la tercera función. «... este esquema recuerda, en sus líneas fundamentales, el sistema de división tripartita funcional, cuyo imperio sobre el pensamiento religioso de los indoeuropeos mostró G. Dumézil» (Vernant, op. cit., 1975: 37). Así, pues, incluso en el área helénica, donde la herencia indoeuropea está muy diluida en el crisol cultural de las sociedades del Egeo, aparece también la fórmula trifuncional.

Concluyamos tan largo viaje a través de las mitologías de los pueblos indoeuropeos, que recorre tiempos y espacios diferentes, en el área escandirava de la sociedad medieval europea.

Gran parte de las noticias de que disponemos sobre la antigua mitología escandinava nos han llegado por textos elaborados durante la Edad Media: las antiguas Eddas, las numerosas sagas... Mención aparte merecería Snorri Sturlusson -autor de la Edda Mayor-, pues su obra es imprescindible para el conocimiento de la antigua religión escandinava. Pero ahora interesa detenerse en su ilustre contemporáneo Saxo Gramático, autor danés de los comienzos del siglo xirl que, aunque más conocido por su Gesta Danorum, nos ha dejado la Saga de Handingus, donde emerge, esta vez en forma novelada, la estructura tripartita de la religión indoeuropea. Dumézil ha dicho de esta saga: «lejos de transmitirnos el recuerdo adornado de guerras, de invasiones, de movimientos étnicos o culturales, esta leyenda no es sino la forma que adoptó, en las regiones del norte, un viejo mito indoeuropeo atestiguado asimismo en la India y en Roma, un mito que explicaba cómo se formó al principio 
de los tiempos la sociedad ideal, sociedad de los antepasados (Roma) o sociedad de los dioses (India, Escandinavia): dos grupos de dioses o de hombres eran al principio distintos y se yuxtaponían, uno que encarnaba a la vez la soberanía religiosa y jurídica y la fuerza combatiente, el otro la fecundidad y la riqueza; estos dos grupos se opusieron en un conflicto serio e indeciso, hasta que un acuerdo introdujo definitivamente a los representantes del segundo grupo o el segundo grupo entero en la sociedad del primero, que así quedó completa, en condiciones de garantizar armoniosamente las tres funciones reconocidas fundamentales por la ideología indoeuropea» (Dumézil, 1973, a: 50-1).

Hemos visto cómo la religión legitimaba decisivamente el Orden Social, de tal suerte que la sociedad de los hombres era concebida a imagen y semejanza de la sociedad de los dioses. En la Teología, en los mitos, en epopeyas y leyendas, así quedaba expuesto.

Ello implica, igualmente, que quien en la sociedad de los hombres tiene a su cargo el mantenimiento de ésta debe, asimismo, recibir una legitimación de índole religiosa. Cuando las condiciones del Orden Social quedan definidas por arquetipos míticos y religiosos, cuando es una «realidad» de carácter sacro la que confiere durabilidad a la realidad profana, el responsable de ésta ha de estar necesariamente en contacto con aquélla. El rey en las sociedades indoeuropeas es dios o sacerdote, pero en cualquier caso se encuentra apegado a la esfera de lo sagrado. «El rex indoeuropeo es mucho más religioso que político. Su misión no es la de comandar, la de ejercer un poder, sino la de determinar las reglas, fijar en sentido propio "derecho". De suerte que el rex así definido se parece más a un sacerdote que a un soberano. Es esta realeza la que los Celtas y los Itálicos de una parte, los Indios de otra, han conservado» (Benveniste, op. cit., 1969, tomo II: 15). Efectivamente, ya hemos visto que las tres funciones atribuidas al rey en las culturas indoeuropeas concluyen en un aspecto central; el adecuado cumplimiento de las tres funciones contribuye al mantenimiento y la perpetuación de la comunidad a cuyo cargo está el rey. La realeza es la máxima garantía del Orden Social. Por ello ha de tener carácter sacro.

El rex latino, que tiene su correspondencia en el término sánscrito raj, está dotado de atributos políticos y religiosos. El poder del «rey de reyes», del emperador iraní (el ksa), es de esencia mística. En el área helénica, el basileus asume prerrogativas mágico-religiosas: entre sus atributos está el kudos, la superioridad mágica. Por otra parte, el símbolo de la más antigua realeza helénica es el cetro, el bastón del mensajero portador de una palabra autorizada por los dioses.

Consagrado el Poder con una realidad trascendente al orden de los mortales, los pueblos indoeuropeos han construido su particular Teología Política. Las categorías poder y religión confluyen en una misma figura, la del rey, quien tiene a su cargo el mantenimiento del Orden de la sociedad. Como 
quiera que el Orden Social es la premisa necesaria para el automantenimiento y la reproducción social, el Poder que garantiza el Orden ha de ser de naturaleza sacra: sacralizando el Poder, la sociedad afirma su voluntad de eternidad y su temor a la muerte. Específicamente para el caso que estamos tratando: al concebirse el Orden como cumplimiento de las tres funciones básicas de toda comunidad indoeuropea, la Teología Política indoeuropea viene determinada por aquella misma estructura. Los indoeuropeos no conciben la figura de su Soberanía Político-Religiosa sino a partir de su jerarquizado despliegue en las tres funciones.

\section{La Identidad Colectiva de los Pueblos Indoeuropeos}

«El país que ya no tenga leyendas — dice el poeta- está condenado a morir de frío. Es harto posible. Pero el pueblo que no tuviera mitos estaría ya muerto. La función de la clase particular de leyendas que son los mitos es, en efecto, expresar dramáticamente la ideología de que vive la sociedad, mantener ante su conciencia no sólo los valores que reconoce y los ideales que persigue de generación en generación, sino ante todo su ser y su estructura mismos, los elementos, los vínculos, los equilibrios, las tensiones que la constituyen; justificar, en fin, las reglas y las prácticas tradicionales sin las cuales todo lo suyo se dispersaría» (Dumézil, 1971: 15). La Sociedad —el Orden Social-, las instituciones humanas, los papeles que desempeñan los individuos, las funciones colectivas que se deben cumplir, son emanaciones de lo sagrado, pues sólo así adquieren sentido y significatividad plena para la conciencia. Además, la sociedad humana, que se sabe intrínsecamente precaria, se equipara simbólicamente al arquetipo celeste para, de este modo, imaginarse perpetua y eterna. El terror colectivo a la muerte y la colectiva voluntad de supervivencia impregnan de sacralidad las construcciones sociales de los humanos.

«Frente a la temporalidad mortal de la existencia humana, frente a la multiplicada incertidumbre y riesgo subyacente a la historicidad de toda cultura particular, la maquinación mítico-ritual de su propia Identidad Colectiva es un argumento básico y nuclear de cada sociedad concreta» (Moya, sin fecha: 10). Con la categoría Identidad Colectiva se quiere aquí aludir al conjunto de representaciones simbólicas que configuran un tipo particular de humanidad y definen una cierta figura del Orden Social que se pretende trascendente a su propia caducidad temporal. En efecto, ninguna sociedad se puede perpetuar y reproducir sin un determinado ajuste de sus estructuras. Ajuste estructural que viene denominado como Orden Social. Mientras que los procesos conflictuales generan movimientos de cambio, el mantenimiento del Orden Social contribuye a la pura reproducción de las mismas estructuras. Así, pues, sólo identificándose colectivamente con aquella figura del Orden 
Social, que la maquinación de la Identidad Colectiva ha definido en una sociedad concreta, los miembros de esa sociedad, impulsados por su voluntad de supervivencia, se sueñan eternos. "Toda estructura social es algo que se engendra, se desarrolla y perece en el tiempo. Por eso mismo, toda estructura afirma simbólicamente la angustia mortal del sujeto humano frente a la contingencia y al azar de su propia existencia histórica» (Moya, en Jiménez y Moya, 1978: 508). La figura del Orden Social, específico producto mítico de la Identidad Colectiva, define las condiciones en que la reproducción social de lo Mismo es posible. «El Orden Social es la imagen trascendental de la existencia social objetiva en cuanto sociedad existente y perdurable, garantizando la perduración del sujeto humano en su identidad así establecida» (Moya, op. cit.: 508).

La Identidad Colectiva dada en su sociedad ofrece a sus miembros la posibilidad de autoidentificación con aquella figura del Orden Social que niega su inmanente caducidad. «Pensándose como trascendente al mortal azar histórico, la sociedad se sabe a Sí Misma y sueña su identidad como figura de eternidad" (Moya, ídem: 509).

La finitud de la vida colectiva es negada por el Sujeto Social en la etnocéntrica representación de su Identidad Colectiva. Por ello, esta representación ha de ser necesariamente de carácter religioso, sagrada. Pues solamente las realidades de orden sacro trascienden la temporalidad erosiva, que siempre termina por destruir las realidades profanas. La figura trascendente del Orden Social es de naturaleza mítico-religiosa. De esta manera, míticamente, la sacralizada representación de la Identidad Colectiva de una sociedad particular se concibe como perdurable. La representación religiosa de la Identidad Colectiva, diciendo míticamente las condiciones en que es posible un cierto Orden Social, cancela el terror tanático de los mortales que la comparten, pues el Orden Social es la condición necesaria de la reproducción social de lo Mismo. El terror pánico a la muerte colectiva se resuelve religiosa, míticamente, en la sacralizada representación de la Identidad Colectiva.

En resumen, el discurso en que se contiene la representación de la Identidad Colectiva es necesariamente un discurso mítico-religioso. Las Ideologías Religiosas y la Teología Política de cada sociedad consagran como realidad última una determinada figura del Orden Social que hace posible la autoidentificación del sujeto colectivo consigo mismo para la «infinita» reproducción de sus más esenciales estructuras.

El pensamiento social y religioso de los pueblos indoeuropeos viene absolutamente determinado por la estructura mitológica de las tres funciones. En toda la extensa área cultural y geográfica a donde han llegado los pueblos indoeuropeos se puede fácilmente reconocer una misma estructura que informa sus concepciones políticas, sociales, religiosas, etc. Tal estructura supone, en lo esencial, que la buena marcha de la sociedad y su mejor ordenación sólo quedan aseguradas cuando se cumplen en esa sociedad las tres funciones so- 
beranas: la administración político-religiosa, el ejercicio bélico de las armas y la productividad material. Desde la India a Escandinavia, los pueblos que pertenecen a la familia lingüística indoeuropea han reiterado ampliamente esta concepción del mundo y de la sociedad. Lo que Georges Dumézil denomina «ideología religiosa de las tres funciones» no es sino la imagen ideal, mítica, del Orden Social de los pueblos indoeuropeos. «Según esta ideología, no sólo la sociedad, sino el mundo, en su totalidad o reducido a tal o cual de sus mecanismos particulares, no pueden vivir, durar y reproducirse más que por colaboración armoniosa de tres funciones jerarquizadas: a la cabeza, el poder soberano, que se manifiesta con dos aspectos, uno mágico y el otro jurídico; luego, la fuerza física, principalmente la del guerrero; por último, la fecundidad de los humanos, de los animales y de los campos, con el cortejo de nociones afines: salud, belleza, juventud y voluptuosidad...» (Lévy-Strauss, 1980: 17). Con ello, en la ideología religiosa de las tres funciones se encuentra la representación dominante de la Identidad Colectiva de las primeras sociedades indoeuropeas. Los indoeuropeos se identifican colectivamente con esa figura del Orden Social que supone el juego armonioso de las tres funciones soberanas. Sacerdotes, guerreros y campesinos (agricultores-ganaderos) son los tres grupos sociales que tienen a su cargo el cumplimiento de las tres funciones. La pautada conjunción de estos tres grupos sociales asegura el mantenimiento y la mayor perdurabilidad de las sociedades indoeuropeas. Los indoeuropeos definen el Orden Social a partir de la articulación funcionalmente tripartita de sus sociedades: cuando sacerdotes, guerreros y productores realizan estrictamente, ritualmente, las tareas a ellos encomendadas, la sociedad funciona de forma ajustada, se eliminan conflictos y es posible la reproducción colectiva. La ideología religiosa de las tres funciones -representación dominante de la Identidad Colectiva de los indoeuropeos- asegura simbólicamente la supervivencia colectiva de aquellas sociedades.

La más prístina manifestación de esa ideología se encuentra en el pensamiento teológico. Y, efectivamente, ello no podía ser de otra manera. La Teología Política de los indoeuropeos es el espacio discursivo donde primariamente se encuentra la representación dominante de su Identidad Colectiva. Definiendo míticamente la sociedad de los dioses, se elabora el modelo ejemplar de la sociedad de los humanos; de este modo, la sociedad de los humanos se quiere eterna como la sociedad divina que le ha servido de modelo. Por ello, son los dioses soberanos de los indoeuropeos los primeros representantes arquetípicos de las tres funciones. Las tríadas de los dioses soberanos (Mitra-Varuna, Indra y Nasatya; Odinn, Thorr y Freyr; Júpiter, Marte y Quirino), con sus respectivas funciones, constituyen el arquetipo político y social, el modelo absoluto que deben seguir las sociedades indoeuropeas para su mejor articulación y ordenación persistente. La Teología Política de los indoeuropeos consagra entonces como realidad última la imagen del ritualizado Orden Social de las tres funciones soberanas. 
Ahora bien, la estructura mítica de las tres funciones informa decisivamente las elaboraciones mentales de los pueblos indoeuropeos. Con el transcurrir del tiempo, tal estructura mítica se hace presente en toda suerte de leyendas, epopeyas y narraciones pretendidamente históricas. En definitiva, se trata también de relatos míticos. Y la diversidad formal de estas míticas narraciones, los diferentes personajes que en ellas aparecen, las diversas situaciones en que se encuentran, no ocultan de ningún modo que la estructura de fondo es la misma. La estructura lógica del mito se impone rápidamente a la diversidad formal.

A partir de una prehistoria compartida, en los sucesivos procesos de migración y conquista, de expansión cultural, en definitiva, de los pueblos indoeuropeos, se ha conservado y transmitido una estructura mítica y religiosa que por doquier se impone y domina sus formas de pensamiento. Georges Dumézil acotó analíticamente esta estructura y, después de establecer la identidad estructural de las elaboraciones religiosas de la India, Escandinavia y Roma, constató la presencia de aquella misma estructura en una multitud de parcelas pertenecientes a pueblos de lengua indoeuropea.

Por ello, la representación dominante de la Identidad Colectiva de los pueblos indoeuropeos, primitivamente expresada en el discurso de la Teología Política, aparece después en toda otra suerte de manifestaciones literarias. Manifestaciones literarias míticamente determinadas por la misma estructura. Tríadas de dioses soberanos; tríadas de personajes épicos; confluencia de tres razas a la fundación de una nueva sociedad; con este tipo de fórmulas, los pueblos indoeuropeos simbolizan su idea de la perfección social. La sociedad de las tres funciones es la sociedad más perfecta que les cabe imaginar a los pueblos indoeuropeos. En consecuencia, estos pueblos se identifican colectivamente con esta figura ternaria de la perfección social. 


\section{BIBLIOGRAFIA}

Benveniste, E. (1969): Le vocabulaire des institutions indo-européennes, París, Les Editions de Minuit.

Berger, P. (1971): Para una teoría sociológica de la religión, Barcelona, Ed. Kairos. CÉSAR, C. J. (1798): Comentarios de la guerra de Francia, Madrid, Imprenta Real. DumézIL, G. (1969): Idées Romaines, Paris, Editions Gallimard.

DumézIL, G. (1970): Los dioses de los indoeuropeos, Barcelona, Editorial Seix Barral.

- (1971): El destino del guerrero, México, Editorial Siglo XXI.

- (1973): Los dioses de los germanos, México, Editorial Siglo XXI.

Dumézil, G. (1973 a): Del mito a la novela, México, Fondo de Cultura Económica. - (1977): Mito y epopeya, Barcelona, Editorial Seix Barral.

DumÉzIL, G. (1979): Mariages indo-européennes, París, Edit. Payot.

Eliade, M. (1973): Mito y realidad, Barcelona, Editorial Guadarrama.

- (1978): Historia de las creencias y las ideas religiosas, tomo I, Madrid, Ediciones Cristiandad.

HOMERo (1976): La odisea, Madrid, Editora Nacional.

JIMÉNEZ y MOYa (1978): Teoría sociológica contemporánea, Madrid, Edit. Tecnos.

Lévi-Strauss, C. (1980): "Respuesta a Georges Dumézil", Vuelta, núm. 49, México.

Moya, C. (sin fecha): Una alternativa analítica, escrito inédito.

Vernant, J. P., et al. (1975): Las nociones de estructura y génesis, tomo III, Buenos Aires, Edic. Nueva Visión. 
